\title{
Practice Recommendations for Infection Prevention and Control Related to Foot Care in Healthcare Settings
}

\section{This position statement was developed by members of the IPAC Canada Reprocessing Interest Group:} Prinicipal Authors: Clare Barry BN,MSc,CIC ${ }^{1}$, Anne Augustin MLT,CIC ${ }^{2,3}$, Tina Stacey-Works MLT,CIC ${ }^{4,5}$, Merlee Steele-Rodway RN,CERT ${ }^{6,7}$, Nicole Kenny BSc Assoc Chem ${ }^{1}$, Donna Perron RN,BScN,CIC ${ }^{2,8}$, Mandy Deeves RN, BScN, MPH, CIC ${ }^{1,2}$, Laura Farrell $\mathrm{BSc}, \mathrm{BEd}, \mathrm{CPHI}(\mathrm{C}), \mathrm{ClC}^{2,9}$, Romy Burgess Burfitt RN ${ }^{3,10}$, and Andrea Skeoch RN ${ }^{11}$

\author{
Affiliations: \\ 1 IPAC Canada - Greater Toronto Area \\ 2 Public Health Ontario \\ ${ }^{3}$ IPAC Canada - Peel and Neighbouring Area \\ ${ }^{4}$ Halton Healthcare \\ ${ }^{5}$ IPAC Canada - Central South Ontario \\ ${ }^{6}$ Canadian Association of Medical Devices Reprocessing \\ 7 IPAC Canada - Newfoundland and Labrador \\ ${ }^{8}$ IPAC Canada - Eastern Ontario \\ ${ }^{9}$ IPAC Canada - Western Ontario \\ ${ }^{10}$ College of Health Studies \\ ${ }^{11}$ IPAC Canada - Southern Alberta
}

Publication Date: November 2019

Disclaimer: This document was developed by IPAC Canada based on best available evidence at the time of publication to provide advice to Infection Prevention and Control Professionals. The application and use of this document are the responsibility of the user. IPAC Canada assumes no liability resulting from any such application or use.

\section{BACKGROUND}

Foot care devices have been linked to healthcare-associated infections and outbreaks [1-7]. The goal is to provide infection prevention and control (IPAC) practice recommendations for foot care. This will include cleaning, disinfection and sterilization processes, and management of the environment, as well as client and healthcare provider safety.

\section{Stakeholders}

Healthcare providers performing foot care in any healthcare setting, which includes, but is not limited to, care provided in private homes, clinics, and healthcare settings.

This practice document is written for healthcare providers who provide foot care or reprocess critical foot care devices, and is not intended to address foot care practice performed by the client or the client's family.
Companion documents: IPAC Canada Position Statement on Reprocessing of Critical Foot Care Devices (2019) and the IPAC Canada Audit Tool for Foot Care.

\section{PRACTICE STATEMENT}

- The IPAC Canada Position Statement: Reprocessing of Critical Foot Care Devices shall be followed.

Clients expect and require safe care regardless of where foot care is performed. Therefore, each client interaction requires a sterile set of critical foot care equipment/ devices [8-10].

- Reusable foot care equipment/devices are considered critical devices [8-14].

- All healthcare providers are responsible for ensuring that the client is not placed at risk of infection when reusing any foot care equipment/devices during the provision of care. 
- If a facility (e.g., acute care, retirement home, longterm care home), a client within the facility, or a client's family contract the foot care services of an independent provider, the facilities' management should perform a risk assessment and review of the external provider's services to ensure the current national, provincial and regulatory body standards and/or guidelines related to IPAC are practiced, including but not limited to medical device reprocessing [8-12].

\section{Determining the best reprocessing option:}

In-house reprocessing may not be cost-effective or timely for small establishments, and other options should be considered. When determining which reprocessing option to use; an organizational risk assessment should

be performed [11].

Some points to consider:

- Types and frequency of procedures performed

- Types and complexity of the equipment

- Liability - complete responsibility for all aspects of reprocessing

- Policies and procedures for all aspects of reprocessing - Quality assurance program

- Staff to do the reprocessing; space to do the reprocessing

- Ongoing staff education, training and competency to reprocess and operate equipment

- Level of education is dependent on the organization risk assessment

- Cost

- Capital to purchase reprocessing equipment (e.g., steam sterilizer, ultrasonic cleaner [optional], incubator for biological indicators)

- Operating costs include but are not limited to: biological indicators, chemical indicators, preventative maintenance program for equipment, packaging system, labels, staff time, education and training of staff, physical space, and meeting provincial/territorial/ national Occupational Health standards.

Options to achieve a sterile set of foot care equipment/ devices for each client interaction include:

Option 1: Use single-use sterile disposable equipment/ devices and discard after use; they must not be reprocessed, reused, or kept for future use with either the same client or different client $[10,15,16]$.

Option 2: Reusable foot care equipment/devices reprocessed using the contracted services of a centralized Medical Device Reprocessing Department (MDRD). The contracted MDRD meets the CSA standards and has qualified technicians to perform the reprocessing (cleaning and steam sterilization).

Option 3: The healthcare provider chooses to reprocess reusable equipment/devices themselves following the guidance outlined in IPAC Canada's Position Statement on Reprocessing of Critical Foot Care Devices.

\section{MANAGEMENT OF THE ENVIRONMENTS}

There are two environments: the client care environment and the reprocessing area.

Foot care procedures shall be performed on clean surfaces. All healthcare providers shall have a documented IPAC plan with written policies and procedures, based on current standards and guidelines, for cleaning and disinfection of environmental surfaces and other equipment between clients [5, 12].

Healthcare providers undertaking reprocessing activities need to understand the potential for cross-contamination in the environment during the course of providing care and during cleaning, disinfection and sterilization procedures. The environment shall be designed to allow for one-way work flow from dirty to clean, with clear separation of clean and dirty instruments [12]. Regular, documented cleaning schedules shall be in place in the following areas:

- clinical care area

- reprocessing area

- where sterile supplies are stored [12].

\section{Client Care Area}

Cleaning and disinfection of the client care environment shall be performed between clients [5, 17].

- In any setting, client care environment includes the area the healthcare provider designates for foot care, and encompasses all surfaces, which may be touched by the client or the healthcare provider during care. This includes furniture (e.g., chair, table, exam table, footstool, toolbox/cart), any other equipment such as podiatry rotary tool/device, and any surface contaminated by nail clippings or nail dust.

- Cleaning and disinfection of all client care environments shall be performed with a hospital/healthcare grade low-level hospital/healthcare disinfectant that has a Drug Identification Number (DIN) from Health Canada. Manufacturer's instructions shall be followed $[12,17]$.

- Linens or disposable covers (e.g., paper covers, blue pads) shall be changed or discarded after each use prior to cleaning and disinfection of the treatment surface being protected $[11,15,18]$

\section{Supplies and Accessories}

- If a podiatry rotary tool/device is required for the provision of care, a dust-extracting drill is recommended to decrease environmental contamination and occupational exposure $[19,20]$. All devices used for foot care, including devices used for electronic nail filing, shall be intended by the manufacturer for use on humans [10,12-14].

- Sanding [emery] bands shall be single use and disposed after use $[9,10,13]$.

- The dust bags and filters should be changed according to their manufacturer's instructions for use (MIFUs) and in compliance with current standards and legislation.

- If footbaths or basins are used to clean the feet, a single-use plastic liner is to be used and discarded after use, and the 
basin is to be cleaned and disinfected as per manufacturer's instructions after each use.

- Products and linen should be stored in a clean area in a manner that prevents contamination (e.g., closed container, cupboard), until time of use.

- Sterile supplies/equipment shall be used for procedures that require sterility.

- Single-use antiseptics are preferred - to be used once only on a single client.

- Multi-dose antiseptics, medications, creams, lotions, should be single-client use [5]. Dispense in a manner that prevents contamination of the product. If a single use is not available, then use an applicator (sterile if indicated) or medicine cup to dispense from the multi-use product to prevent contamination. Date and label the multi-use product when opened. Products shall be monitored for expiration date and discarded when beyond use date has been met [15]. In addition, discard contaminated or potentially contaminated products and never top-up solutions $[13,21]$.

- Single-dose vials for injectable medications are preferred and shall only be used for one client $[11,22,23]$.

- If multi-dose vials for injection or infusion are used, they shall be dedicated to a single client and labelled with client's name. Vials shall be dated, stored and discarded according to manufacturer's recommendations, or within 28 days $[11,22,23]$.

- All needles and syringes shall be single use [11,22].

- Never re-enter a vial with a used needle or used syringe $[11,22,23]$.

- Single-use items including, but not limited to emery boards, orange sticks, podiatry [rotary] tool/device discs, and blades shall be discarded after use $[9,10,13]$.

- The following items shall be available at the point of care:

- Hand-washing sink and/or alcohol-based hand rub (ABHR)

- Personal Protective Equipment (PPE)

- Gloves, gowns, and face protection

- PPE shall be single use

- Puncture-resistant biohazard container that meets provincial regulatory requirements [24].

- There shall be a designated soiled area. In a clinic setting, the soiled area shall be separate from the client care area and the clean supply storage.

- There shall be a covered, puncture-resistant bin for collecting soiled instruments.

\section{Storage of Sterile Medical Devices and Supplies}

- Sterile packs, instruments, and supplies shall be stored outside of the client care area in a clean, dry, dust-free area $[11,12]$.

- Maintain clean, sterile supplies in a closed container, shelf or drawer, away from the floor, waste, debris, drains, moisture, and sinks to prevent contamination. Maintain sterility until the time of use [10-12]. Product is not sterile if packaging is open, damaged, or wet. Check before using. Do not use if packaging integrity is in question [12].

- There shall be sufficient equipment available to allow for safe reprocessing practices.

\section{Dedicated Reprocessing Area}

- The reprocessing work area shall include a dedicated cleaning sink and be physically separate from the client care area and the designated clean and sterile storage areas. There shall be a designated one-way workflow from decontamination to the disinfection or sterilization area to prevent soiled items from coming into contact with clean and sterile items [12].

- Work surfaces shall be seamless and composed of a nonporous material so they can be cleaned, disinfected, and dried. These work surfaces shall be cleaned and low-level disinfected daily, or when visibly soiled [12].

- Environmental room monitoring is recommended: temperature $\left(18-20^{\circ} \mathrm{C}\right.$ for decontamination; $18-23^{\circ} \mathrm{C}$ for clean areas), relative humidity (30-60\%), and air pressure/ flow [12].

- Wherever cleaning and reprocessing is performed, follow the manufacturers' directions for use to ensure the occupational health and safety $(\mathrm{OH} \& \mathrm{~S})$ regulations are met for air quality.

- Chemicals shall be labelled, stored, and handled correctly according to the safety data sheets (SDS).

- Hand hygiene and eye wash facilities shall be readily available [12,25-27].

- Manufacturers' instructions for equipment maintenance and quality control shall be followed for all reprocessing equipment and documented.

TABLE 1: Cleaning schedule

for clinics and reprocessing areas [12,17].

\begin{tabular}{|l|l|}
\hline \multicolumn{1}{|c|}{ Space } & \multicolumn{1}{c|}{ Frequency } \\
\hline $\begin{array}{l}\text { Sinks, counters, bathrooms } \\
\text { and floors }\end{array}$ & Daily and when visibly soiled \\
\hline $\begin{array}{l}\text { Shelves: } \\
\text { in reprocessing areas } \\
\text { in sterile storage areas } \\
\text { in clinical areas }\end{array}$ & $\begin{array}{l}\text { Daily } \\
\text { Every } 3 \text { months } \\
\text { Monthly }\end{array}$ \\
\hline Walls and light fixtures & Every 6 months \\
\hline
\end{tabular}

\section{Reprocessing of Foot Care Devices/Equipment}

In the delivery of foot care services, equipment often intentionally or unintentionally comes into contact with blood, body fluids, or non-intact skin, requiring sterilization. Therefore, it is imperative to manage all equipment as if it has been contaminated. Soil is not always readily visible. IPAC best practices indicate there should be one reprocessing system for all equipment for any client [15]. 
Reprocessing of reusable foot care equipment/devices shall meet MIFUs, current national Canadian Standards Association (CSA) standards, and the guidelines from the Public Health Agency of Canada (PHAC/Health Canada) and provinces $[9,12]$.

Spaulding's classification is used to determine how a device will be reprocessed, according to the perceived risk level [28]. Devices that may penetrate into sterile tissues or the vascular system require sterilization. Devices that contact non-intact skin, but do not come in contact with sterile tissues require, at a minimum, high-level disinfection. Sterilization is preferred $[8,9,12]$.

For minimum levels of reprocessing, including the Adapted Spaulding's Classification of foot care equipment/devices, the management of burrs and use of podiatry rotary tools/devices, see the "Reprocessing of Critical Foot Care Devices" Position Statement.

\section{Cleaning}

All policies and procedures shall be written, adhered to, and in compliance with current provincial Occupational Health and Safety acts and associated regulations, provincial or federal guidelines for reprocessing of medical devices.

\section{Selection and Use of Cleaning Agents}

- Cleaning agent(s) shall be chosen based on the intended use and used as per manufacturers' instructions.

- Choice of cleaning agent(s) and cleaning process shall render equipment safe for handling during subsequent reprocessing steps.

\section{Pre-Cleaning of Equipment}

- Gross soil (e.g., tissue, blood) shall be removed immediately at point-of-use [12].

- If immediate pre-cleaning cannot be conducted, one of the following processes shall be used to prevent organic matter from drying: kept moist by using a lint-free towel moistened with water, soaking, or a pre-clean foam or gel product [12].

- Pre-cleaning is required before sending instruments out to a contracted facility for reprocessing.

\section{Cleaning of Equipment}

- Cleaning by manual or mechanical cleaning methods may be used (e.g., ultrasonic cleaner, washer/disinfector) after gross soil has been removed; followed by a thorough rinse.

- The equipment/device manufacturer's cleaning instructions shall be followed, including specifications for detergent type, water temperature and cleaning methods.

- Detergents and/or enzymatic detergents do not have a DIN from Health Canada

- If used, cleaner-disinfectant shall have a DIN from Health Canada and be used as per the MIFU.

- Document that cleaning was performed according to MIFU.

- Household products have not been validated for cleaning medical devices and shall not be used.
- The process for cleaning shall include written protocols [12].

- The cleaning process should include:

- disassembly (if required),

- sorting and soaking,

- physical removal of soil,

- rinsing,

- drying,

- physical inspection,

- corrosion reduction/lubrication (if required),

- packaging (if required)

\section{STERILIZATION}

Where the level of reprocessing recommended by the manufacturer is not in agreement with Spaulding's criteria [28], the more stringent level shall be used. For all sterilization, the end user shall follow CSA Z314-18 Canadian medical device reprocessing.

\section{STEAM STERILIZATION}

CSA standards for steam sterilization shall be met.

- Steam sterilization is the preferred method [12]. If purchasing a new sterilizer, "the preferred method of sterilization for heat-tolerant critical devices should be dynamic air removal steam sterilization rather than gravity displacement." [12]

- It is essential that healthcare professionals performing reprocessing of reusable foot care devices shall be knowledgeable and follow provincial and national standards for medical device reprocessing (e.g., Canadian Standard Association [CSA] - Z314-18 Canadian medical device reprocessing available on line at www.csa.ca). If unable to meet the required standards, other options shall be considered. For example, use only disposable equipment, or contract for a service by a centralized reprocessing facility.

- A steam sterilizer shall only be purchased from a qualified manufacturer (e.g., shall be licensed for sale in Canada and appear on the Medical Devices Active Licence List [MDALL]) and shall include a printout or data logger, have a wrapped cycle, and manufacturer's manual for care, operation and preventative maintenance.

- Follow the manufacturer's guidelines regarding the type of water to be used in the steam sterilizer.

Unacceptable methods of sterilization include ImmediateUse Steam Sterilization (IUSS - formerly referred to as flash sterilization), glass bead sterilizer, microwave oven, boiling, Chemiclave, steam sterilizers without printouts or electronic recording, and ultraviolet irradiation $[8,9,12]$.

Multifunctional domestic appliances are also unacceptable for sterilization such as dishwashers, pressure cookers, and toaster ovens.

If an existing steam sterilizer does not have a printer or electronic recording device (USB), CSA recommends that there is a plan to update or replace the sterilizer to bring this into compliance with current standards. 
Note: The use of liquid chemicals for sterilization of instruments is not supported for critical equipment/devices that are used for sterile procedures due to the limitations in maintaining sterility to point of use [29]. "Devices cannot be wrapped or adequately contained during processing in a liquid chemical sterilant to maintain sterility following processing and during storage." [29,30].

\section{STORAGE AND TRANSPORTATION \\ Storage}

- Clean/sterile supplies/medical devices:

- Shall be stored in containers that can be easily cleaned (i.e., NOT in cardboard or paper boxes) [12].

External corrugated cardboard shall not be kept in clean storage area.

- Shall not be stored on the floor, on a shelf below stored liquids, on window sills, or under sinks, but away from debris, drains, moisture, and vermin to prevent contamination and maintain sterility until the time of use $[8,9,11,12]$.

- Shall not be stored in an area accessible to clients $[2,5,12]$ (e.g., client care rooms, procedure/exam rooms, public corridors).

- Shall be stored within the temperature and relative humidity ranges specified on the manufacturer's label (typically relative humidity maintained between $30 \%$ and 60\%) [12].

- Storage space shall be sufficient to ensure packages are not crushed or damaged by overcrowding [11,12].

- Windows and doors in the storage area shall be kept closed [11].

- Stock should be rotated, so that oldest stock can be used first [12].

- There shall be no eating and drinking in the areas where clean/sterile supplies/medical devices are stored or handled or where client care is delivered $[8,9,12]$.

\section{Transportation}

- Distribution of medical devices shall be performed using clean and either puncture-resistant enclosed or covered transportation carts, bins, and totes [12].

- Bins and plastic totes that are used for transportation of clean/sterile supplies/medical devices shall be cleaned between each use and when visibly soiled [12].

- Bins/containers used to transport soiled medical equipment/ devices shall be cleaned after each use [12].

- Clean/sterile supplies/medical devices shall be transported separately from soiled supplies/medical devices to ensure the integrity of the clean/sterile supplies/medical devices are not compromised (e.g., two sealable rigid containers; one labelled "clean" for clean/sterile supplies/medical devices and one labelled "dirty" for soiled supplies/medical devices)

- Dirty reusable medical devices shall be pre-cleaned at pointof-use.

\section{QUALITY ASSURANCE}

- There shall be a designated individual who is responsible for reprocessing.

- Healthcare providers involved in reprocessing shall receive education and training appropriate to the volume and complexity of equipment to be reprocessed.

- Education is to be done on hire, annually and when new equipment or devices are purchased. Ongoing education and auditing shall include theoretical and practical components [10, 31,32].

- Develop written policies and procedures for sterilization of medical equipment/devices used in the clinical office setting that include cleaning, drying, inspection, disassembly, wrapping, sealing and labelling, transportation, and storage.

- Ensure that the manufacturer's instructions for installation, operation, cleaning, and preventive maintenance of the sterilizing equipment are followed.

- Ensure that sterilization cycles are in accordance with recommended parameters for proper reprocessing of all reusable instruments and as per MIFUs.

- Ensure documentation of sterilization parameters, for steam sterilization processes. Required documentation shall be kept as per CSA Z314-18 or provincial regulations [12].

- Test all sterilizers for performance using physical, chemical, and biological monitors and indicators as per CSA Z314-18 standards [12].

- A procedure shall be established for the recall of improperly reprocessed medical equipment/devices, i.e., in the event of a failed biological indicator (BI).

- There shall be an audit schedule set up to monitor environmental cleaning, Routine Practices and reprocessing procedures. Refer to Infection Prevention and Control Audit for Foot Care. Audit Toolkit Version 2 [32].

- An incident management process shall be in place to safely manage potential cross-contamination in the environment during the course of providing care and during cleaning, disinfection, and sterilization procedures. If there is a reported visual or cause for any cross-contamination, the processes shall be stopped, assessed with a root cause analysis, corrected, and verified to ensure safety. All devices involved in this process shall be cleaned and reprocessed prior to use on a client.

\section{OCCUPATIONAL HEALTH \& SAFETY}

There shall be written policies and procedures outlining healthcare provider safety while providing foot care and/or reprocessing foot care equipment. These documents are to be in compliance with current provincial/national Occupational Health and Safety acts and associated regulations. Employers and educators shall ensure proper training and compliance with the recommendations, which are to be ongoing and audited. All healthcare providers shall adhere to the policies and procedures, and shall be aware of the possible health effects of their exposure to infectious agents and/or chemicals [12]. 


\section{Immunization and TB Testing}

- For all healthcare providers providing foot care and/or reprocessing foot care instrumentation the following is recommended:

- Hepatitis B immunization, unless they have documented immunity to Hepatitis B [12,24,33].

- All immunizations are kept current for measles, mumps, rubella, and annual influenza [12].

- TB testing to follow current Canadian Tuberculosis Standards, 7th Edition 2013 [34] or provincial/ organizational policies.

\section{Sharps Management}

- There shall be written measures and procedures to prevent and manage injuries from sharp objects [12,24,33,35].

- All sharps shall be handled in the following manner:

- Place item for disposal in designated puncture-resistant container.

- Do not recap needles.

- Do not manually bend or break needles.

- Take care when handling glass or other fragile objects.

- Dispose of all sharps as per provincial/municipal legislation.

- Follow current Transportation of Dangerous Goods Regulations [36].

\section{Blood and Body Fluids}

- Policies and procedures are written and readily available for immediate management of exposure to blood and body fluids $[12,24,33]$.

- Healthcare providers are trained in the actions to follow for exposure. If a healthcare provider member has a bloodborne exposure, report and follow your organizational and or provincial Occupational Health and Safety Accidental Bloodborne Exposure Protocol.

- Healthcare providers shall be trained in management of a blood or body fluid spill [35].

\section{Hand Hygiene}

As stated by the Public Health Agency of Canada, "Adherence to hand hygiene recommendations is the single most important practice for preventing the transmission of microorganisms in health care and directly contributes to client safety." [18]. Adherence to proper hand hygiene (technique and opportunities) is the responsibility of all individuals involved in healthcare.

Each health care provider is accountable to follow the hand hygiene recommendations of their respective profession.

There are two methods of performing hand hygiene:

$[25,26,37,38]$

- Visible soil on the hands: hand hygiene is performed with soap and water.

- No visible soil on the hands: healthcare provider may use either soap and water or an alcohol-based rub.
Hand and arm jewelry or nail enhancements should not be worn when providing client care; skin care for the provider is promoted.

Refer to the IPAC Canada's Hand Hygiene Practice Recommendations [38].

\section{Education for Routine Practices}

Healthcare providers are to receive education and training on the consistent use of Routine Practices, including the personal risk assessment and hand hygiene, to prevent exposure to blood and body substances in client care and reprocessing areas.

- Eating/drinking, storage of food, smoking, application of cosmetics or lip balm, and handling of contact lenses in the client care or reprocessing area is not permitted [12].

- There shall be no storage of personal effects, including food and drink, in client care areas or the reprocessing area.

- Personal Protective Equipment (PPE)

- A personal risk assessment is performed based on best practices to determine the PPE required.

- PPE shall be readily available $[18,39]$.

- There shall be training and auditing that the PPE is worn correctly.

- When reprocessing equipment:

- PPE shall be worn for reprocessing activities according to CSA Z314-18 [12]

- The following PPE shall be worn for cleaning and handling of contaminated equipment:

- Gloves:

- Glove use does not negate the need for hand hygiene $[12,18,25,26,39]$.

- Choice of glove is dependent on the setting and a risk assessment of the types of tasks to be done $[12,18,39]$.

- Face protection worn (i.e., full face shield OR fluidimpervious face mask and protective eyewear) and an impermeable gown [12].

\section{- Hair Covering:}

- Personnel shall confine all hair by wearing a clean hood or hair covering. Hair coverings shall be changed at least daily and more frequently if soiled. Bouffant and hood style covers are preferred [12].

- In the clinical area:

- A personal risk assessment is performed based on best practices to determine the PPE required for the specific foot care procedure being performed.

- Choice of respiratory protection is dependent upon a risk assessment of the types of procedures to be done (e.g., using a rotary tool/device) and your provincial Occupational Health and Safety legislation, or your local public health authority.

- N95 respirators are generally recommended for nail reduction, particularly if the equipment does not include dust extraction or water spray [40]. 
- Wear eye protection and surgical mask or fit-tested, seal-checked N95 respirator to reduce the possibility of inhaling nail dust generated during reduction of nails. The exposure of nail dust has been associated with conditions such as conjunctivitis, rhinitis, and occupational lung disease [19,41-44].

- Surgical masks or N95 respirators should fit snugly and be worn for one client only $[39,41]$.

- Respirator Fit Testing:

- Suppliers can often provide N95 respirator fit testing or contact an agency responsible for $\mathrm{OH} \& \mathrm{~S}$ or IPAC in your area for information about fit testing.

- Further information may be found via local IPAC Canada chapter(s) or the Canadian Centre for Occupational Health \& Safety.

- All PPE is removed and disposed of appropriately on completion of the task for which it is worn and before leaving the reprocessing area or when leaving the client's bedside/room, or chair.

\section{Workplace Safety}

- Workplace safety information is to be readily accessible for any chemicals used.

- Information on WHMIS is available from the Health Canada website at: https:/canada.ca/en/health-canada/services/ environmental-workplace-health/occupational-health-safety/ workplace-hazardous-materials-information-system.html

- If there is a risk of exposure to a biological and/or chemical agent, eye wash stations shall be provided and healthcare provider shall be trained on the use of eye wash station [27],

\section{- Work restriction:}

o Skin shall be intact. Healthcare providers who have weeping dermatitis or exudative lesions shall refrain from providing direct client care or handling client equipment until the condition is healed.

o Healthcare providers who have respiratory problems (e.g., asthma) should be assessed by $\mathrm{OH} \& \mathrm{~S}$ or personal healthcare provider (e.g., physician, nurse practitioner) prior to working with chemical disinfectants or cleaning agents [12].

\section{GLOSSARY:}

Autoclave: Steam sterilizer

Client: Includes patient, client, resident

Critical Medical Equipment/Devices: Medical equipment/ devices that enter sterile tissues, including the vascular system (e.g., biopsy forceps, foot care equipment, dental hand pieces). Critical medical equipment/devices present a high risk of infection if the equipment/device is contaminated with any microorganism, including bacterial spores. Reprocessing critical equipment/devices involves meticulous cleaning followed by sterilization [11].

Drug Identification Number (DIN): In Canada, low-level disinfectants are regulated as drugs under the Food and Drugs Act and regulations. Disinfectant manufacturers shall obtain a
DIN from Health Canada prior to marketing, which ensures that labelling and supporting data have been provided and that it has undergone and passed a review of its formulation, labelling and instructions for use [8]

Detergent: A cleaning agent that increases the ability of water to penetrate organic material and breakdown greases and dirt. Detergents are needed to allow effective cleaning to take place. Use only detergents that are compatible with instruments being cleaned. Follow the detergent manufacturer's instructions for concentration, temperature, and recommended contact time. Eye Protection: A device that covers the eyes and is used by healthcare providers to protect the eyes when it is anticipated that a procedure or care activity is likely to generate splashes or sprays of blood, body fluids, secretions or excretions, or within two metres of a coughing client. Eye protection includes safety glasses, safety goggles, face shields, and visors [39]. Prescription glasses are not eye protection.

Foot Care: Routine foot care includes a clinical assessment of the feet, education for the client/patient/resident, and care that only involves the epidermal layer of the skin or nails. Routine care may include the filing of corns or calluses, the filing or trimming of nails, and skin care. Invasive foot care includes contact with non-intact skin and surgical interventions with entry into or contact with the epidermal, dermal, deep fascial, and osseous structures. Foot care is performed by healthcare providers (e.g., chiropodists, podiatrists, nurses, advanced trained foot care nurses) within their defined scope of practice.

Healthcare Provider: Any healthcare professional delivering foot care service to a client as well as those performing reprocessing duties.

Healthcare Setting: Any location where healthcare is provided, including emergency care, pre-hospital care, hospitals, long-term care, home care, ambulatory care, and facilities and locations in the community where care is provided. Examples of healthcare settings include, but are not limited to, the following settings that shall be able to meet the reprocessing standards outlined in this document:

- Acute care/emergency/trauma hospitals

- Medical/surgical/ambulatory care clinics with or without overnight stay or observation

- All physician offices

- Nursing homes, long-term care, and assisted living facilities

- Rehabilitation facilities

- Group homes or residential facilities

- Hospice care facilities

- Educational institutions

- Correctional facilities

- Private homes where foot care is provided

- Foot care clinics

Hospital Disinfectant: A low-level disinfectant that has a DIN from Health Canada indicating its approval for use in Canadian healthcare settings. Hospital disinfectants were previously referred to as "hospital-grade disinfectants."

Low-Level Disinfection (LLD): Level of disinfection required 
when processing non-invasive medical equipment (i.e., non-critical equipment) and some environmental surfaces. Equipment and surfaces shall be thoroughly cleaned prior to low-level disinfection [8].

Manufacturer's Instructions for Use (MIFU): The written instructions for use provided by the manufacturer or distributor of a product that contain the necessary information for the safe and effective use of the product [12].

Medical Devices Active Licence Listing (MDALL): Reference tool for licensed medical devices in Canada by Health Canada, accessible at https://health-products.canada.ca/mdall-limh/ index-eng.jsp

N95 Respirator: A personal protective device that is worn on the face and covers the nose and mouth to reduce the wearer's risk of inhaling airborne particles. A NIOSH-certified N95 respirator filters particles one micron in size, has $95 \%$ filter efficiency and provides a tight facial seal with less than $10 \%$ leak [18].

Note: The wearer shall do a seal-check: A procedure that the healthcare provider shall perform each time an N95 respirator is worn to ensure it fits the wearer's face correctly to provide adequate respiratory protection. The healthcare provider shall receive training on how to perform a seal-check correctly [39,45].

Personal Protective Equipment: Specialized clothing or equipment used by workers to provide a barrier or shield to prevent potential exposure to infectious microorganisms, and exposure to chemicals or physical hazards used or present during decontamination, sterilization, or provision of care. Note: PPE includes and is not limited to gowns, gloves, masks, facial protection (e.g., masks, eye protection, face shields, or masks with visor attachments), respirators, and hair covering [12].

Personal Risk Assessment: An evaluation of the interaction of the healthcare provider, the client/patient/resident and the client/patient/resident environment to assess and analyze the potential for exposure to infectious disease.

Routine Practices: Infection prevention and control practices to be used with all clients during all care, to prevent and control transmission of microorganisms in all healthcare settings.

Routine Practices shall be incorporated into the culture of each healthcare setting and into the daily practice of each healthcare provider to protect both the client and healthcare provider [18,39].

Semi-Critical Medical Equipment/Device: Medical equipment/ device that comes in contact with non-intact skin or mucous membranes, but ordinarily does not penetrate them (e.g., respiratory therapy equipment, transrectal probes, and specula). Reprocessing semi-critical equipment/devices involves meticulous cleaning followed by, at a minimum, high-level disinfection. Sterilization is preferred [8].

Single-Use/Disposable: A term given to medical equipment/ devices designated by the manufacturer for single-use only. Single-use equipment/devices shall not be reprocessed [8].

Steam Sterilization: The basic principle of steam sterilization, as accomplished in an autoclave, is to expose each item to direct steam contact at the required temperature and pressure for the specified time. There are four parameters of steam sterilization: steam, pressure, temperature, and time [27]. Steam sterilization, dynamic air removal type: One of two types of sterilization cycles in which air is removed from the chamber and the load by a series of pressure and vacuum excursions (pre-vacuum cycle) or by a series of steam flushes and pressure pulses above atmospheric pressure (steam-flush-pressure-pulse cycle) [29].

Sterilization: The level of reprocessing required for critical medical equipment/devices. Sterilization results in the destruction of all forms of microbial life including bacteria, viruses, spores and fungi. Equipment/devices shall be cleaned thoroughly before effective sterilization can take place [8].

Surgical mask: A device that covers the nose and mouth is secured in the back and is used by healthcare providers to protect the mucous membranes of the nose and mouth [11].

\section{As per Canadian Standards Association}

"SHALL" is used to express a requirement, i.e., a provision that the user is obliged to satisfy in order to comply with the standard; "SHOULD" is used to express a recommendation, or that which is advised but not required; and

"MAY" is used to express an option, or that which is permissible within the limits of the standard, an advisory or optional statement

\section{REFERENCES}

1. Centers for Disease Control and Prevention. HealthcareAssociated Hepatitis B and C Outbreaks Reported to Centres for Disease Control and Prevention (CDC) 2008-2017; 2018 Aug 21. Retrieved from: https://www.cdc.gov/hepatitis/outbreaks/pdfs/ HealthcarelnvestigationTable.pdf

2. Wise ME, Marquez P, Sharapov U, et al. (2012). Outbreak of acute hepatitis $B$ virus infections associated with podiatric care at a long-term care facility. Am J Infect Control, 40(1), 8-21.

3. Wenger JD, Spika JS, Smithwick RW, et al. (1990). Outbreak of Mycobacteruim chelonae infection associated with use of jet injectors. JAMA, 264(3), 373-376.

4. Rutala, WA, Weber DJ, Thomann CA. (1987). Outbreak of wound infections following outpatient podiatric surgery due to contaminated bone drills. Foot Ankle, 7(6),350-419.

5. Wise ME, Bancroft E, Clement EJ, et al. (2015). Infection prevention and control in the podiatric medical setting: Challenges to providing consistently safe care. J Am Podiatr Med Assoc., 105(3), 264-272.

6. Hathaway S, Marquez P, Bancroft E. Hepatitis B outbreak in a skilled nursing facility. Acute Communicable Disease Control 2008: Special Studies Report, Los Angeles County Dept. of Public Health: 43. Retrieved from: http://publichealth.lacounty.gov/wwwfiles/ph/dcp/ acd/2008SpecialStudies.pdf

7. Calles DL, Collier MG, Khudyakov Y, et al. (2017). Hepatitis $C$ virus transmission in a skilled nursing facility, North Dakota, 2013. Am J Infect Control, (45),126-32. 
8. Ontario Agency for Health Protection and Promotion (Public Health Ontario). Provincial Infectious Diseases Advisory Committee.

Best practices for cleaning, disinfection and sterilization of medical equipment/devices. 3rd ed. Toronto, ON: Queen's Printer for Ontario; May 2013. Retrieved from:

http://www.publichealthontario.ca/en/eRepository/PIDAC Cleaning_Disinfection_and_Sterilization_2013.pdf

9. Best practices for cleaning, disinfection and sterilization in health authorities. Vancouver: British Columbia Ministry of Health. Patient Client Safety Branch; 2011. Retrieved from: http://www.health.gov.bc.ca/library/publications/year/2011/ Best-practice-guidelines-cleaning.pdf

10. Canadian Association of Foot Care Nurses/Association canadienne des infirmieres et infirmiers en soins de pieds. National competencies for advanced nursing foot care in Canada. 2017. Retrieved from: https:/cafcn.ca/wp-content/ uploads/CAFCN-National-Competencies-for-AdvancedNursing-Foot-Care.pdf

11. Ontario Agency for Health Protection and Promotion (Public Health Ontario). Infection prevention and control for clinical office practice. 1st revision. Toronto, ON: Queen's Printer for Ontario; 2015. Retrieved from: www.publichealthontario.ca/en/eRepository/IPAC_Clinical_ Office_Practice_2013.pdf

12. Canadian Standards Association. CAN/CSA-Z314-18 Canadian medical device reprocessing. Rexdale, ON: Canadian Standards Association; 2018.

13. Public Health Agency of Canada. Infection control guidelines: Foot care by providers. Can Commun Dis Rep 1997;(23S8). Retrieved from: http://publications.gc.ca/collections/ collection_2016/aspc-phac/HP3-1-23-S8-eng.pdf

14. Alberta Health Services: Infection prevention and control best practices for foot care devices. 2013. Retrieved from: https://www.albertahealthservices.ca/ipc/hi-ipc-footcarebpg.pdf

15. Center for Disease Control and Prevention. Guide to infection prevention for outpatient podiatry settings. 2018. Retrieved from: https://www.cdc.gov/infectioncontrol/pdf/ Podiatry-Guide_508.pdf

16. Popalayar A, Stafford J, Ogunremi T, Dunn K. (2019). Infection Prevention in personal services settings: Evidence, gaps and the way forward. CCDR, 45/1.

17. Ontario Agency for Health Protection and Promotion (Public Health Ontario), Provincial Infectious Diseases Advisory Committee. Best practices for environmental cleaning for prevention and control of infections in all health care settings. 3rd ed. Toronto, ON:

Queen's Printer for Ontario; 2018. Retrieved from: https://www.publichealthontario.ca/-/media/documents/ bp-environmental-cleaning.pdf

18. Public Health Agency of Canada. Routine practices and additional precautions for preventing the transmission of infection in health care. Ottawa, ON: Her Majesty the
Queen in Right of Canada; 2012. Retrieved from: https://www.canada.ca/en/public-health/services/publications/ diseases-conditions/routine-practices-precautions-healthcareassociated-infections/introduction.html

19. Burrow JG, McLarnon NA. (2006). World at work: Evidence based risk management of nail dust in chiropodists and podiatrists. Occup Environ Med, 63(10), 713-716.

20. United States Environmental Protection Agency.

Recommended Cleaning and Disinfection Procedures for Foot Spa Basins in Salons: Step-by-step instructions for disinfecting pedicure foot spa equipment. 2018.

Retrieved from: https://www.epa.gov/pesticides/ recommended-cleaning-and-disinfection-proceduresfoot-spa-basins-salons

21. IPAC Canada Position Statement on Medical Gels. 2017. Retrieved from: https://ipac-canada.org/photos/custom/ Members/pdf/17Dec_Medical\%20Gel_Final.pdf

22. APIC Position Paper: Safe injection, infusion, and medication vial practices in health care. 2016. Retrieved from: https://www.apic.org/Resource_/TinyMceFileManager/ Position_Statements/2016APICSIPPositionPaper.pdf

23. Ontario Agency for Health Protection and Promotion (Public Health Ontario), Provincial Infectious Diseases Advisory Committee. Updated guidance on the use of multidose vials; 2015. Retrieved from: www.publichealthontario.ca/-/media/ documents/multidose-vials-guidance.pdf?la $=$ en

24. Government of Canada. Canadian Centre for Occupational Health and Safety. Needlestick and sharps injuries; 2019. Retrieved from: https://www.ccohs.ca/oshanswers/diseases/ needlestick_injuries.html

25. Public Health Agency of Canada. Hand hygiene practices in healthcare settings. Ottawa, ON: Her Majesty the Queen in Right of Canada; 2012. Retrieved from http://publications. gc.ca/collections/collection_2012/aspc-phac/HP40-742012-eng.pdf

26. Ontario Agency for Health Protection and Promotion (Public Health Ontario), Provincial Infectious Diseases Advisory Committee. Best Practices for Hand Hygiene in All Health Care Settings. 4th ed. Toronto, ON: Queen's Printer for Ontario; April 2014. Retrieved from: http://www. publichealthontario.ca/en/eRepository/2010-12\%20BP\%20 Hand\%20Hygiene.pdf

27. Canadian Centre for Occupational Health and Safety. Eye wash station; 2019. Retrieved from: https://www.ccohs.ca/ oshanswers/safety_haz/emer_showers.html

28. Spaulding EH. (1972). Chemical disinfection and antisepsis in the hospital. J Hosp Res, 9(1), 5-31.

29. Center for Disease Control (CDC). Guideline for disinfection and sterilization in healthcare facilities, 2008. Update: 2019 May. Retrieved from: https://www.cdc.gov/infectioncontrol/ pdf/guidelines/disinfection-guidelines-H.pdf

30. Rutala WA, Weber DJ. (2019). Disinfection, sterilization, and antisepsis: An overview. Am J Infect Control, 47S, A3-A9. 
31. Ontario Agency for Health Protection and Promotion (Public Health Ontario), Cividino M, Moore D, Deeves M. Recommendations for education, training and certification for reprocessing in clinical office settings. Toronto, ON: Queen's Printer for Ontario; 2016. Retrieved from: https://www.publichealthontario.ca/-/media/documents/ recommendations-certification-clinical-office.pdf?la =en

32. IPAC Canada. Infection prevention and control audit for foot care. Audit Toolkit Version 2. 2015 Jan. Retrieved from: https://ipac-canada.org/ipac-canada-products-2.php

33. Ontario Hospital Association and the Ontario Medical Association Joint Communicable Diseases Surveillance Protocols Committee. Blood-borne disease surveillance protocol for Ontario hospitals. 2018. Retrieved from: https://www.oha.com/Documents/Blood\%20Borne\%20 Diseases\%20Protocol\%20(November\%202018).pdf

34. Public Health Agency of Canada, The Lung Association, Canadian Thoracic Society. Canadian tuberculosis standards, 7th ed. 2014. Retrieved from: https://www. canada.ca/en/public-health/services/infectious-diseases/ canadian-tuberculosis-standards-7th-edition.html

35. Public Health Agency of Canada (PHAC). (1997). Infection control guidelines preventing the transmission of bloodborne pathogens in healthcare and public service settings. Can Commun Dis Rep, 23 (Suppl 3), i-vii, 1-43, i-vii, 1-52.

36. Government of Canada. Transportation of Dangerous Goods Regulations. 2019. Retrieved from: https://www.tc.gc.ca/ eng/tdg/clear-download-372.htm

37. Public Health Ontario. Just clean your hands (JCYH) program. Retrieved from: https://www.publichealthontario. ca/en/health-topics/infection-prevention-control/ hand-hygiene

38. IPAC Canada. IPAC Canada practice recommendation: Hand hygiene in healthcare settings. 2017. Retrieved from: https://ipac-canada.org/photos/custom/ Members/pdf/17JulHand\%20Hygiene\%20Practice\%20 Recommendations_final.pdf
39. Ontario Agency for Health Protection and Promotion, Provincial Infectious Diseases Advisory Committee. Routine practices and additional precautions in all settings. 3rd ed. Toronto, ON: Queen's Printer for Ontario; 2012. Retrieved from: http://www.publichealthontario.ca/en/eRepository/ RPAP_All_HealthCare_Settings_Eng2012.pdf

40. College of Chiropody of Ontario. Standards of practice for chiropodists and podiatrists infection prevention and control. 2018. Retrieved from: http://www.cocoo.on.ca/ pdf/standards/standard-infection.pdf

41. Smith J, MacDougall C, Johnstone J, Copes RA, Schwartz B, Garber GE. (2016). Effectiveness of N95 respirators versus surgical masks in protecting workers from acute respiratory infection: systematic review and meta-analysis. CMAJ, 188(8), 567-574.

42. Donaldson CL, Carline T, Brown DM, Gilmour PS, Donaldson K. (2002). Toenail Dust Particles: a Potential Inhalation Hazard to Podiatrists? Ann Occup Hyg, 46(Suppl.1), 365-368.

43. Tinley PD, Eddy K, \& Collier P. (2014). Contaminants in human nail dust: an occupational hazard in podiatry?

J Foot Ankle Res, 7(15), 1-7.

44. Nowicka D, Nawrot U, Włodarczyk K, et al. (2016). Detection of dermatophytes in human nail and skin dust produced during podiatric treatments in people without typical clinical signs of mycoses. Mycoses, 59(6), 379-82.

45. Canadian Standards Association. CAN/CSA-Z94.4-18 Selection, Use, and Care of Respirators: Occupational Health \& Safety. Rexdale, Ont.: Canadian Standards Association; 2018.

This document is endorsed by the Canadian Association of Medical Device Reprocessing.

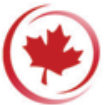

